\title{
INTRODUCTION
}

\section{Valuing Learning and Valuing SoTL}

In this issue, Maria Guglietti asserts that students must value a particular skill or piece of knowledge if they are to learn it well. This is a simple, yet compelling, assertion. We have probably all put time and effort into learning things we did not really value, but did that learning "stick"? We doubt it.

Still, numerous questions emanate from Guglietti's assertion. Notably, how do we come to value that which we have yet to learn? This question reaches well beyond Guglietti's context, which is the journalism classroom. It is also relevant to the entire field of the scholarship of teaching and learning (SoTL). It touches upon Elizabeth Marquis' paper that probes the extent to which SoTL institutes can help SoTL become woven into an institution's culture. In this weaving process, we are asking people to value something they have yet to learn - the nature and full potential of SoTL.

Janice Miller-Young and Michelle Yeo remind us that the value of any research goes up when theory and methodology align. Here is another seemingly simple assertion that is more complex that it looks, especially for a relatively nascent field in which many of us are learning a host of theories and methods that are new to us. As might be the case with Guglietti's students, valuing these theories and methods requires a bit of a leap of faith for us.

Also, value is determined more by a cognitive process than by some absolute property of the thing. We create and ascribe value. We are reminded of this in the paper by Rachel Spronken-Smith, Nell Buissink-Smith, Carol Bond, and Gabrielle Grigg. They interviewed people five years after graduation about the things they valued regarding their university education. It turned out that their perceived value was closely linked to their expectations about the purpose of higher education. We value that which fulfills our positive expectations. Correspondingly, many of us have worked to create positive expectations regarding the potential of SoTL and, in turn, enhance its perceived value.

It is interesting to think about how we can enhance the perceived value of an educational experience. For Joanne Benham Rennick, when those experiences involve immersion in a new culture, we can apply the principles forwarded by Dewey, Freire, and Mezirow to make those experiences truly transformational for students. Value is attained by thoughtfully developing a humanitarian and humble perspective when entering new cultures, or for that matter, when trumpeting the value of SoTL.

On a relatively grand scale, Sean Brawley, Jennifer Clark, Chris Dixon, Lisa Ford, Erik Nielsen, Shawn Ross, and Stuart Upton explore the ways we ascertain the value of a national program. How do we conduct an audit that allows us to draw conclusions re- 
garding the value of something with a broad scope? The authors discovered that this is a particularly labour-intensive process. However, if we value the learning we are trying to engender, we will engage in the process.

And for Earle Abrahamson, his impressions of the first EuroSoTL conference are shaped in no small part by the experience of being with a group of people who share these values and perspectives.

Finally, Kathryn Sutherland's poem challenges us to reflect on the connotations of our common language for considering the value of our work. Why is violence interwoven into how we think about the effects of teaching, learning, and SoTL? This subtext doesn't align well with our ideals or what we say we value.

For those of us who have espoused the views that learning matters, that good teaching can facilitate learning, and that SoTL can show us the way to good teaching and learning, we are always focused on the perceived value of these elements. As more people see this value, the more we will see SoTL woven into our everyday academic lives. The papers in this issue of Teaching \& Learning Inquiry take us one step closer to this reality.

Gary Poole is a Professor in the School of Population and Public Health and a Senior Scholar in the Centre for Health Education Scholarship at the University of British Columbia.

Nancy Chick is University Chair in Teaching and Learning, and Academic Director of the Taylor Institute for Teaching and Learning at the University of Calgary. 